\title{
Metaphorical Competence: A Neglected Component of Communicative Competence
}

\author{
Masoud Khalili Sabet \\ English Department, University of Guilan, Iran \\ E-mail: sabetma2002@yahoo.com \\ Marjaneh Tavakoli (Corresponding author) \\ English Department, University of Guilan (International Campus), Iran \\ E-mail: Marjanehtavakkoli@gmail.com
}

Received: 04-11-2015

Accepted: 28-01-2016

Published: 31-01-2016

doi:10.7575/aiac.ijels.v.4n.1p.32

URL: http://dx.doi.org/10.7575/aiac.ijels.v.4n.1p.32

\begin{abstract}
The ability to comprehend and use metaphors in L2 which is referred to as metaphorical competence is an important issue in second language acquisition. Metaphors are so pervasive in our life that we might not realize their presence and simply neglect them even in our first language. Different models of communicative competence have been suggested in the literature; however, the model of Bachman and Palmer (1996) is the one considered in the present study. It includes two major nodes of organizational and pragmatic competences. Under the organizational competence are grammatical and textual competences, and pragmatic competence includes illocutionary and sociolinguistic competences. In this paper it is argued that among the many competences required to be considered proficient in a language, metaphorical competence is also central. As such, after illuminating the concept of metaphor and metaphorical competence, some models of communicative competence (CC) are presented. Moreover, in line with Littlemore and Low (2006), it is emphasized that metaphorical competence which is present in most of the components of $\mathrm{CC}$ should receive more attention in L2 classrooms. In fact, it is concluded that having an acceptable metaphorical competence contributes to the learners' overall communicative competence.
\end{abstract}

Keywords: Metaphor, Metaphorical competence, Communicative competence, L2

\section{Introduction}

The concept of metaphor and metaphorical competence in L2 learning might appear unimportant or even unessential at the first sight and many EFL instructors or practitioners have paid lip service to it. The ability to produce or comprehend metaphors in the target language gain significance when thinking about thought, language and cognition; however, self-expression seems not to be very much dependent on metaphors. As held by Danesi (1994), an emerging issue in Second Language Acquisition (SLA) has been the extent to which second language learners acquire the capability of expressing their thoughts and ideas in the target language with the application of culturally suitable and acceptable figurative language.

There are different definitions for the concept of metaphorical competence. Nacey (2010) defined metaphorical competence as "the ability to understand and produce metaphor" (p.32). In other words, a person who is able to comprehend metaphors produced by others and who can also use it in communication is considered as metaphorically competent.

As evident in the Iranian EFL classroom, the focus of Second Language Teaching (SLT) has been on the development of learners' linguistic and communicative competences, with the results of having learners who are almost capable in these areas. However, as mentioned by Danesi (1992), there is a gap in these pedagogical attempts which relates to something beyond grammatical and communicative competence or proficiency. It is apparent that while L2 learners might possess high verbal fluency, they are far behind the native speakers in terms of conceptual fluency. In fact, even though L2 learners speak or write with a good command of formal language, they mostly think in and utilize the conceptual system of their L1, i.e. they use L2 vocabularies and structure as manifestations of their L1 concepts. This may have two major outcomes: on the one hand, if there is accordance with their L1 conceptual system and the way in which TL concepts are utilized L2 learners' discourse coincide with L2 texts which are culturally appropriate. On the other hand, in case of discrepancy between the two systems learners may encounter problems since there will be an irregularity between L2 learners' language form and the conceptual system of the TL. In other words, conceptual fluency $(\mathrm{CF})$ is what the L2 learners' discourse often does not exhibit. 
As indicated by Danesi (1992), metaphorical competence (MC) is as vital as linguistic and communicative competences, since it is closely connected to the ways in which a culture conceptually sets its world. As such, it can be claimed that human thinking and acting, as well as communication is largely based on conceptual system and embedding metaphors is a key feature of native speaker competence.

In 1980s and with the publication of the book Metaphors We Live by Lakoff and Johnson (1980), the study of metaphor and its relation to cognition and language moved toward a new direction. Their basic argument was that metaphors are not just rhetorical devices or tools for elaborating language, but they are a basic facet of human cognition. Based on Lakoff and Johnson's theory, human perception and actions are mediated through and governed by a conceptual system which is non-linguistic in nature and is central in our understanding of reality. Because of the metaphorical relationship between concepts in our conceptual system, metaphor is regarded as experiencing and understanding one thing in terms of another (Lakoff \& Johnson, 1980). This point of view is called experimentalism, which holds that the nature and structure of reality is basically linked to our perception, understanding, and action. It should be noted that metaphorical language and metaphors are utilized in our everyday communication, in education, politics, and even in science. Many of the universal concepts such as, time, state, quantity are understood through metaphorical relations. They are rooted in our observable and concrete daily experiences and also our world knowledge and then projected onto unobservable and abstract concepts.

In a survey of the psycholinguistic literature on figurative language, Gibbs (1994; as cited in Lantolf \& Thorne, 2006) found that if context was appropriate, people mostly processed the metaphorical features of language compared to its literal meaning. This leads to the conclusion that metaphors are an important property of communication. A pioneer researcher with reference to the application of conceptual system in education and language studies is Beck (1982). In recent years and in a number of studies, Danesi $(1992,1994,1995)$ investigated the application of Lakeoff and Johnson's theory in the field of second language teaching and learning. He argued that for having a good command of language and learning it in its full potential, we must be able to access the conceptual system of that language and also encode our expressions on the basis of that system. This is a neglected aspect of foreign or second language teaching which is named metaphorical competence (MC) by Danesi (1992). He believed that having attained a native-like MC, an L2 learner can be considered fluent in L2. He further pointed out that up to that time language pedagogy had not conveyed this capability in second language learners.

According to Conceptual Fluency Theory (Danesi, 1998), which is the theoretical basis of the present study, underlying any linguistic system is a conceptual system which acts as a foundation for both language and our cognitive functioning; in fact, we perceive, think, and speak with the help of our conceptual system. Acquiring another language is, therefore, relied on using L2 conceptual system and the learners must be able to express their thoughts while using the target language conceptual system as native speakers do.

Most L2 learners are not aware of the metaphorical concepts and make use of their L1 conceptual system, literally translating the word or sentence. This can result in misconception or misinterpretation of words or expressions. A major problem of Iranian EFL learners is that even advanced-level students face many difficulties in expressing themselves through metaphors or even in the realm of conceptual skills. Indeed, L2 learners' discourse often lacks conceptual accuracy, since they use the formal structure of English but think in the conceptual system of their L1 (Norafkan, 2013). In case of the congruity between the conceptual system of L1 and L2, culturally appropriate discourse is produced by the learners, but when there is a mismatch between the two systems, communication failure is the result (Danesi, 1999). As pointed out by Lakoff (1993), the main mechanism through which we can comprehend abstract concepts and also do abstract reasoning is metaphor. Therefore, L2 teaching should entail the development of language learners' conceptual system. It seems that having a good knowledge of metaphorical language is one of the challenges facing L2 learners. In fact, figurative language has not received substantial attention from L2 teachers and learners alike, and many of the learners are weak in this regard.

Furthermore, in case of cross-cultural mismatch there may be communication breakdown with the use of language which is grammatically acceptable and correct but pragmatically incorrect and ambiguous. To put it more specifically, Hwang (2008) declared that if we try to raise pragmatic awareness of the learners and make them more familiar with the target language, we can also reduce the social distance between L1 and L2. It must be noted that metaphorical language does not have a secondary role in language teaching and as Lakoff and Johnson (1980) clearly mentioned, metaphorical thinking and metaphorical language are at the heart of everyday linguistic and mental activity. Even a quick glance of texts, whether spoken or written, reveals that we use plenty of metaphors in our daily life and communication; however, we are mostly unaware of using them.

\subsection{Figurative language}

Figurative language is the use of a word or a number of words with non-literal, idiomatic meaning. For instance, in the following sentences:

To capture a bigger share of the market, He came storming into the room.

I think we ought to be pulling together.

the words convey a meaning other than the usual meaning derived from them. Metaphor is the most significant category within figurative language and constitutes the most widely-used type of figurative language. According to Lakoff and 
Johnson (1980), metaphors can create cultural, social and also psychological realities for language users. As we know, linguistic and cultural knowledge are the components of human conceptual system; however, in the past metaphors and idioms were not considered the components of conceptual competence. With the advancements in cognitive linguistics, metaphors and idioms are regarded as unavoidable and necessary elements in human communication. Gibbs (1994; as cited in Norafkan, 2013) contended that the use of figurative language is directly associated with the way we act and interact with other and understand the world. Moreover, Danesi (1999) argued that the use of metaphor is at the heart of abstract thinking through which abstract concepts can be delivered via concrete ones.

\subsection{Metaphor and language use}

Metaphor was traditionally regarded as a matter of language. It was viewed as a set of figurative or non-ordinary linguistic expressions whose meaning could be considered as some set of literal statements. Recently; however, scholars such as Lakoff and Johnson (1980) started a deeper investigation of the subject, examining the possibility that metaphor is both a form of speech and more basically a form of thought, which has basic epistemological functions. Metaphor is, in fact, a way of describing, explaining, and evaluating ideas for the purpose of understanding and communicating abstract ideas in our everyday doings.

The importance of metaphors in language has recently been highlighted in cognitive linguistics, and they have been entering educational practices and materials. Many people consider metaphors as a poetic device and regard it as a figure of speech through which one point is compared to another (Kövecses, 2002). Traditionally, metaphor was conceived of as being the characteristic of language alone; however, this view was challenged by Lakoff and Johnson (1980) who claimed that "metaphor is not a matter of words rather than thought or action ... [and that] our ordinary conceptual system is basically metaphorical in nature" (p. 3). Moreover, Lakoff and Johnson (1980) maintained that metaphorical expressions "provide ways of comprehending experience; they give order to our lives ... and are necessary for making sense of what goes on around us" (pp. 185-186).

Traditionally, metaphors or figurative language was defined as a special way of applying language. Metaphors were mostly related to art and literature. However, this view has undergone a radical change during the last three decades, and metaphors are now considered as a natural part of our language and thought (Goatly, 1997). Through the use of metaphors we can structure our thinking and express varying distinctions in a sentence and choose whether we want to emphasize a point or hide it (ibid.). However, metaphorical sentences have the risk of being misunderstood and this may make communication breakdown. This is less likely to occur in literal sentences in which there is a small gap between the intended meaning and the expressed proposition.

Considering metaphors from a psychological perspective, they highlight semantic creativity in that language users are able to produce and comprehend novel utterances. As such, metaphorical competence entails our ability to recognize the likeliness between apparently incongruent domains and use one domain to understand or talk about another domain.

In cognitive linguistics metaphor is defined as understanding one conceptual domain in relation to or in terms of another conceptual domain. This view of metaphor is further elaborated by Kövecses (2002) as "conceptual domain (A) is conceptual domain (B), which is called a conceptual metaphor" (p. 4). As held by Baily (2003), distinguishing conceptual metaphors from linguistic expressions which are metaphorical is a crucial matter. He explicates conceptual metaphors as "semantic mappings that take two forms of source domain and target domain" (p. 2). The source domain is "the conceptual domain from which we draw metaphorical expressions to understand another conceptual domain, whereas the target domain is the conceptual domain that is understood this way" (Baily, 2003, p. 2). For instance, from the conceptual metaphor of ARGUMENT (target) IS WAR (source) some commonly used linguistic metaphors can be derived, such as He attacked every weak point in my argument. On the other hand, metaphorical linguistic expressions are words that originate from the language of the conceptual domain which is more concrete, i.e. from domain B (Kövecses, 2002).

Metaphors can be spotted in every aspects of our life such as in gestures, drawings or even signs which are employed to convey message (MacArthur, 2012; as cited in Aardal, 2014). In fact, as Ritchie (2006) indicated, with the use of metaphors we can express our thoughts and feelings in ways not possible otherwise. We are surrounded by metaphors in every dimension of our social dealings and they are embedded in our communication. Punter (2007; p. 74) held that "There are barely any words that can be uttered which will not carry and invoke a metaphorical dimension". In spite of the vital role of metaphors in our everyday language, we can argue that they have been neglected in learning and teaching foreign or second languages.

In other words, metaphors are embedded in the language and are means for conveying our intentions. As indicated by Carston (2002), we can say things or convey our thoughts in a more fascinating and creative way by means of metaphors. They are also helpful at times when literal saying of something is difficult for us (Cardoso \& Vieira, 2006; as cited in Aardal, 2014).

It is argued that one of the factors which make foreign language learning process difficult for the learners is metaphors. However, they do not cause difficulty for the native speakers of a language and are commonly used in texts and also in daily conversations. In fact, metaphors are not thought to have a different interpretation than what is commonly understood from the literal meaning of words and expressions used in a language. Kövecses (2002) provides an example to clarify this point. He states that when we use the metaphor 'he is a lion' for describing someone, we aim to 
achieve an artistic or a rhetorical effect, probably because we think that 'he' share specific qualities with a lion, or in other words, we believe that the two entities have some points in common. This metaphorical usage of lion may convey the impression that this person is strong or graceful. Kövecses (2002) further expresses that the metaphorical use of lion is a characteristic of a linguistic expression (p.vii). However, it should be noted that metaphors are not always in the format of $A$ is $B$, in which the resemblance between the two entities is very easy to distinguish.

\subsection{Conceptual metaphor theory}

Lakoff and Johnson (1980) challenged the common thoughts regarding metaphors, discharging the notion of metaphor as a feature of words that is deliberately used, or a kind of figurative language that can be ignored. They were also against the idea of separation of mind and body (Ritchie, 2006). Lakoff and Johnson treated metaphors cognitively and held the view that people constantly use metaphors and they are an inevitable part of human thinking (Kövecses, 2002).

Lakoff and Johnson (1980) held that most people do not conceive of metaphor as a part of everyday language, and regard it as an uncommon type of language. They also argued that most people associate metaphors to words and not to concepts or ideas. They further pointed out that we use metaphors unconsciously and we are not generally aware of our potent conceptual system while interacting with others. Therefore, they stated that as there are metaphors in our conceptual system, creating metaphorical expressions is possible.

It should be born in mind that although conceptual metaphors are considered to be universal, there may be cultural differences in the use and interpretation of metaphors. Lakoff and Johnson (1980, p. 22) positioned that "The most fundamental values in a culture will be coherent with the metaphorical structure of the most fundamental concepts in the culture". Obviously, basic values differ in cultures and this difference might affect the underlying concept of a metaphorical utterance in various cultures. Accordingly, foreign language learners need to have a good understanding of the cultural values of the target language if they want to acquire metaphorical competence. "A knowledge of shared cultural references is necessary (...) to understand and produce the target language with any degree of accuracy" (Lantolf, 1999; as cited in Littlemore \& Low, 2006, p.9). In fact, lack of cultural knowledge may cause difficulties in interpreting metaphorical expressions for foreign language learners.

To sum up, based on the ideas of Lakoff and Johnson (1980), our thought processes are metaphorical and the language which contains metaphors should be processed with the same speed as the language without metaphors. Moreover, they considered mind as a function of body, in that through our bodily experiences we can conceptualize abstract ideas like time and emotions. Therefore, as indicated by Holme (2004, p.23), "the entire apparatus of abstract expressions is metaphorically structured". In addition, language provides the data that can lead to principles of understanding which are metaphoric in nature (Lakoff \& Johnson, 2003, p.116; as cited in Aardal, 2014). This is the reason that metaphors are unavoidable. These lead to the conclusion that Lakoff and Johnson's (1980) research has been central in making it clear that how specific linguistic phenomena work. Their experiments also revealed that metaphors are a major element in the organization of human thought; thus pinpointing the significance of metaphorical competence in any language learning. In fact, learners who lack the ability to think metaphorically they will be considered incompetent.

\subsection{Metaphor and culture}

An important fact in every language is that metaphors have become conventional, i.e. they are commonly utilized in everyday language in a way that not knowing them can cause serious breakdowns in communication. This has automatically made an important space in the culture's conceptual system, and will further highlight the significance of concept awareness in L2 teaching or learning. Danesi (2003) also emphasized that daily usage of abstract concepts make them conventionalized to the point that they lose their connection to the concrete concepts from which they originated. When this happens, these abstract concepts stand as independent and separate concepts which need to be acquired and internalized by learners of that language which in turn widen their conceptual awareness. As such, language learning is not a mere mastery of linguistic and formal aspects, but it also involves the acquisition of conceptual knowledge as an indispensible part of language learning process. There are cases in which a thoroughly new metaphorical system should be acquired; however, sometimes the learners need to modify their existing metaphorical knowledge and this depends on historical and social relations which exist between L1 and L2 (ibid.).

There are specific concepts in each language which are bound to the culture of students and their appropriateness depends on the particular context in which they are used. Norafkan (2013) gave an interesting example of one phrase in Persian which can have different meanings in various English contexts. The example is "I die for you", "I sacrifice myself to you". He further noted that only one of the various cultural concepts conveyed by this phrase in Persian is identical to the English language and it is when someone expresses love to the other person. He also exemplified an erroneous use of this expression by one of his students while talking to his classmate as an evidence for the transfer of L1 conceptual system to L2.Cameron (2003) and Littlemore (2005) held that metaphors are helpful in raising learners' awareness of key concepts in a language.

Tyler (1995) and Hwang (2008) believed that a major cause of communication failure is differences in cross-cultural discourse. Another problem may be pragmatic incompetency of EFL learners. Although communication between or among non-native speakers can be carried out by an acceptable degree of linguistic and communicative competence, not all communication can be satisfactorily conducted without conceptual fluency and that opens up a need for developing EFL learners' conceptual fluency and seeking out useful ways to this end. 
Norafkan (2013) stated that a crucial step in avoiding pragmatic ambiguity and misunderstanding is that language learners should become aware of and familiar with the metaphorical concepts and their linkage.

\section{Conceptual fluency}

Danesi (1995, p. 5) defined conceptual fluency as "the ability to use and comprehend the conceptual concepts of a given language. To be conceptually fluent in a language is to know that language reflects or encodes its concepts on the basis of metaphorical reasoning". In the present paper, conceptual fluency refers to the ability of Iranian EFL learners to comprehend and produce metaphorical expressions in English. More specifically, it refers to their ability to understand metaphorical sentences and idiomatic expressions which convey a certain metaphoric area.

Conceptual competence has been regarded as an inseparable element of communicative competence and it is an important part in L2 learners' ability to make an efficient use of the target language in communicative situations (Andreou \& Galantomos, 2009). Danesi (2003) named three sub-competencies for the conceptual competence, namely metaformal, reflexive, and associative competences. He explained metaformal competence as an individual's ability to use the conceptual system of the target language in an efficient and appropriate way. Reflexive competence refers to the speaker's ability to transform concepts into language categories. Associative competence is related to an individual's knowledge of how abstract concepts are interrelated to cultural terms of a language.

\section{Metaphorical competence}

Metaphorical competence has been described by Danesi (1993) as

the ability to understand and use metaphors in natural communication. The progressing of discourse in metaphorical ways is a basic feature of native speaker competence. It underlies conceptual fluency. As a competence it can be thought about pedagogically in ways that are parallel to other competencies that SLA has traditionally focused on (grammatical and communicative). (p.493)

Metaphorical competence is part of the more general notion of conceptual fluency which is defined by Danesi (2008) as "the ability to express oneself in the L2 while utilizing the conceptual system of the L2, rather than relying primarily on the conceptual system of L1" (p. 243).

Low (1988) held that metaphorical competence includes an individual's ability to produce plausible meanings, knowledge of the boundaries of conventional metaphor, awareness of metaphors that are socially sensible and their multiple layers, and so on. Moreover, based on Littlemore (2001), metaphorical competence comprises four components: metaphor production, mastery on metaphor comprehension, the ability to understand the meaning of metaphor, and finally the speed in so doing.

\subsection{Metaphorical competence in 12}

The term metaphorical competence is typically used in L2 teaching and learning, "as production and interpretation of metaphorical expressions which is often considered more challenging in an L2 than an L1" (Nacey, 2010, p.32). Metaphorical competence is regarded as crucial in achieving fluency in the target language, and being able to metaphorize in L2 can be a sign of the development of communicative fluency in the learners (Danesi, 1994). Having gained metaphorical competence shows itself in circumstances where the learner can interpret idiomatic expressions in L2. If they lack this competence, more effort is needed on their part and there will probably be a breakdown in communication. It should be emphasized that successful interpretation of figurative language is inextricably linked to the cultural knowledge of the learners, the literal meaning of the expression, and also the context in which it is used (Cooper 1999).

In spite of the research findings about the importance of metaphorical competence in L2 learning and teaching, it is still not regarded as a core ability to be developed in the learners, and many students have problems in comprehending and producing metaphors in the target language, and they struggle to use them appropriately. Accordingly, metaphor learning and metaphorical competence should receive more attention on the side of L2 practitioners, and as held by Littlemore and Low (2006), "control over metaphor is one of the essential tools for empowering learners to cope successfully with native speakers" (p.2).

\section{Models of communicative competence}

Within the last two or three decades, a number of models for communicative competence have been proposed starting from the model of Hymes (1972) to those offered by Canale and Swain (1980) or Canale (1983). However, the most comprehensive and widely-used model of communicative competence is that of Bachman (1990) who took a broad view of the term competence believing that it involves the ability to deal with those components of language such as syntax or cohesion which are knowledge-based. Communicative competence is the ability of an individual to function in a communicative situation which is dynamic and interpersonal and requires both linguistic and paralinguistic knowledge (Savignon, 1972).

According to Cazden (1996, as cited in Littlemore \& Low, 2006), Hymes is the father of the notion of communicative competence as he was the first one who provided a clear and explicit definition of this notion. Hymes (1972) considered communicative competence as encompassing grammatical and sociolinguistic competences. In this way, he expanded the Chomskyan notion of competence by positioning grammatical competence in the broader social context of use. 
Communicative competence as depicted by Canale and Swain (1980) and Canale (1983) includes three types of knowledge, i.e. knowledge of grammatical principles, knowledge of proper use of language in social situations for the purpose of fulfilling communicative functions, and knowledge of discoursal aspects related to how well one can combine utterances and communicative functions.

Canale and Swain (1980)

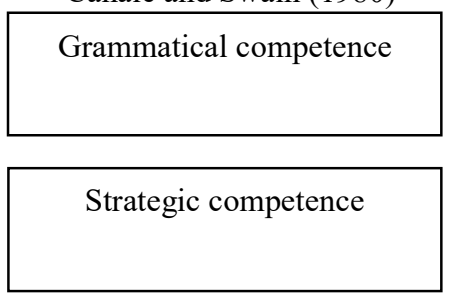

Sociocultural competence
Canale and Swain (1983)

Grammatical competence

Strategic competence

Sociocultural competence

Discourse competence

Figure 1. Canale and Swain's models of communicative competence in 1980 and 1983

Bachman's (1990) model of communicative competence includes two major nodes of organizational and pragmatic competences. Under the organizational competence are grammatical and textual competences, and pragmatic competence includes illocutionary and sociolinguistic competences. In fact what Bachman proposes is an extension of the model of Hymes (1972) who incorporated knowledge of sociolinguistic aspects in the ability to use language appropriately in different communicative situations. In 1996, Bachman and Palmer suggested one of the most comprehensive models of communicative competence which is illustrated below.

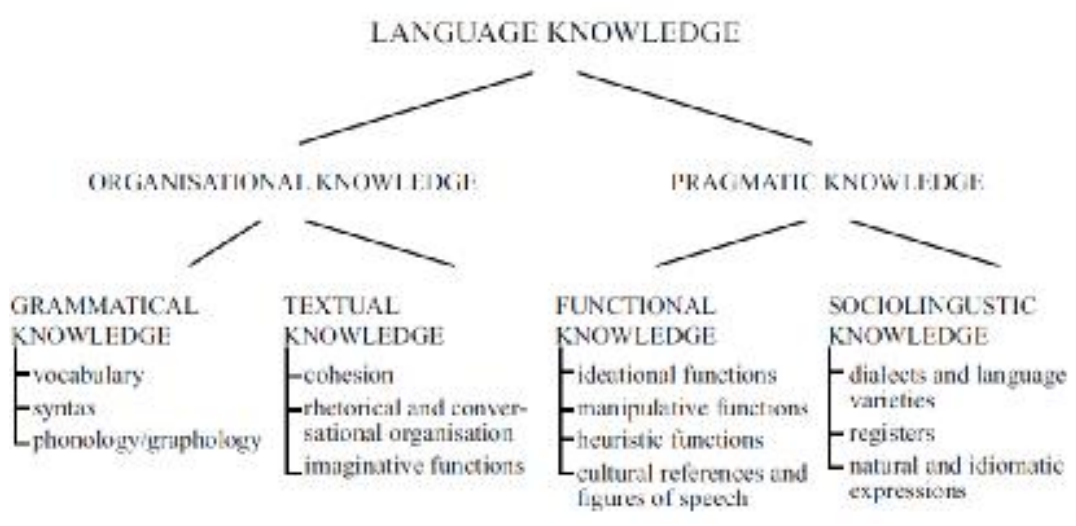

Figure 2. Areas of language knowledge proposed by Bachman and Palmer (1996)

Bachman (1990) preferred to use the term 'communicative language ability' instead of communicative competence stating that the term 'communicative language ability' comprised both competence or knowledge and capacity of an individual to make an appropriate use of that knowledge in various contexts of language use.

As indicated by Littlemore and Low (2006), metaphor is referred to by Bachman only in his description of sociolinguistic competence i.e. in the ability of individuals to interpret cultural references and figures of speech. Nevertheless, Littlemore and Low (2006) in their paper show that metaphors play significant roles in all components of communicative competence, not just in the sociolinguistic element. What was accounted so far indicates that the notion of communicative competence did not have a fixed state and has undergone changes and adaptations in relation to the contexts in which it was used (Borgaric \& Djigunovic, 2007).

\section{Metaphorical competence and its relation to communicative competence}

According to Littlemore and Low (2006), metaphorical competence plays an integral and vital role in all areas of communicative competence. More specifically, metaphorical competence contributes to grammatical, textual, illocutionary, sociolinguistic, and strategic competences. They further acknowledge that many speakers of languages 
make use of metaphors and L2 learners should also be exposed to metaphorical expressions and gain knowledge of their use and application.

As mentioned earlier, metaphorical competence involves the successful and appropriate comprehension and production of metaphors. It is the ability of individuals in understanding one entity in terms of another. The notion of metaphorical competence was also dealt with in Low (1988) who presented a number of skills which were needed to be mastered by learners if they aimed to gain mastery of second or foreign language. In other words, gaining control over the metaphors of a language can be a sign of true mastery of that language and those learners who are able successfully comprehend and use metaphors are thought to be competent learners.

As pointed out by Danesi (1992), there is a close association between metaphorical competence and L2 proficiency and being able to use and comprehend metaphors in a new language is a sign of proficiency in that language. Doiz and Elizari (2013) further held that gaining mastery over figurative or metaphorical language helps L2 learners in developing their receptive and productive fluency in the language they are learning.

\section{Conclusion}

As pointed out by Talebinezhad (2007), the problems experienced by L1 learners when they expressing themselves do not emanate from their linguistic or communicative knowledge, but are rooted in the domain of metaphorical language, and even advanced learners have problems in this area. Danesi (1993) explained that a learner who is able to "convert common experiences into conceptually and linguistically appropriate models" is regarded as conceptually fluent in that language (p. 496).

As mentioned by Littlemore (2001), there are very broad implications in incorporating the notion of conceptual metaphor in second language acquisition, as it is concerned with developing L2 learners' ability to develop their own unconventional metaphors.

If we consider metaphorical competence as an important element within communicative competence, and pay due attention to fostering this competence in L2 learners by incorporating in L2 syllabuses, we can expect to have learners who are able to create novel metaphors approximating or identical to those created by native speakers of the L2. According to Chapeton (2010), this could be possible by systematic instruction of metaphors in L2 classrooms.

In fact, having an acceptable metaphorical competence contributes to the learners' overall communicative competence, in that it is present in all aspects of communicative competence (Haji Maibodi, 2011). As such, integrating metaphor teaching in L2 curriculum can lead into both linguistic and metaphorical competence and to a large extent it can foster a learner's communicative language ability.

\section{References}

Aardal, C. L. (2014). Metaphor comprehension in the EFL classroom. (Unpublished master's thesis). University of Oslo, Norway.

Andreou, G., \& Galantomos, I. (2009). Conceptual competence as a component of second language fluency. $J$ Psycholinguist Res, 38, 587-591. DOI 10.1007/s10936-009-9122-6

Bagarić, V., \& Djigunović, J. M. (2007). Defining communicative competence. Metodika, 8(1), 94-103.

Beck, B. (1982). Root metaphor patterns. Semiotic Inquiry, 2, 86-97.

Cameron, L. (2003). Metaphor in educational discourse, advances in applied linguistics. London, UK: Continuum.

Canale, M. (1983). From communicative competence to communicative language pedagogy. In J. C., Richards \& R. W. Schmidt (Eds.), Language and communication, (pp. 2-27). London: Longman.

Canale, M., \& Swain, M. (1980). Theoretical bases of communicative approaches to second language teaching and testing. Applied Linguistics, 1, 1-47.

Carston, R. (2002). Thoughts and utterances: The pragmatics of explicit communication. Blackwell Publishers Ltd.

Chapeton, C. M. (2010). Metaphor identification in EFL argumentative writing: A corpus-driven study. Folios, 32, 125140.

Cooper, T. (1999). Processing of idioms by L2 learners of English. TESOL Quarterly, 33(2), 233-262.

Danesi, M. (1992). Metaphorical competence in second language acquisition and second language teaching: The neglected dimension. In J. E. Alatis (Ed.), Georgetown University round table on languages and linguistics (pp. 125136). Washington D.C.: Georgetown University Press.

Danesi, M. (1994). Recent research on metaphor and teaching of Italian. Italica, 71, 453464.

Danesi, M. (1995). Learning and teaching languages: The role of conceptual fluency. International Journal of Applied Linguistics, 5(1), 3-20.

Danesi, M. (1998). Sign, thought, and culture: A basic course in semiotics. Toronto: Canadian Scholars' Press.

Danesi, M. (1999). Expanding conceptual fluency theory for second language teaching. Mosaic, 6(4), 16-21. 
Doiz, A., \& Elizari, C. (2013). Metaphoric competence and the acquisition of figurative vocabulary in foreign language learning. ELIA, 13, 47-82.

Goatly, A. (1997). The language of metaphors. London: Routledge.

Haji Maibodi, A. (2011). Enhancing metaphoric competence through the cognitive approach. Journal of English Studies, 1(3), 79-87.

Holme, R. (2004). Mind, metaphor and language teaching. Hampshire and New York: Palgrave Macmillan.

Hwang, C. C. (2008). Pragmatic conventions and intercultural competence. The Linguistics Journal, 3(2), 31-48.

Hymes, D. H. (1972). On communicative competence. In Pride, J. B., \& Holmes, J. (Eds.), Sociolinguistics, (pp. 269293). Baltimore, USA: Penguin Education, Penguin Books Ltd.

Kövecses, Z. (2002). Metaphor- a practical introduction. Oxford: Oxford University Press.

Lakoff, G. (1993). The contemporary theory of metaphor. In A. Ortony (Ed.), Metaphor and thought (2nd Ed.) (pp. 202-251). Cambridge: Cambridge University Press.

Lakoff, G. \& Johnson, M. L. (1980). Metaphors we live by. Chicago: University of Chicago Press.

Lantolf, J. P., \&Thorne, S. L. (2006). Sociocultural theory and the genesis of second language development. Oxford: Oxford University Press.

Littlemore, J. (2001). Metaphoric competence: a language learning strength of students with a holistic cognitive style. TESOL Quarterly, 35(3), 459-491.

Littlemore, J., \& Low, G. (2006). Metaphoric competence and communicative language ability. Applied Linguistics 27(2), 268-294.

Low, G. (1988). On teaching metaphor. Applied Linguistics, 9(2), 125-147.

Nacey, S. (2010). Comparing linguistic metaphors in L1 and L2 English. (Unpublished doctoral dissertation). University of Oslo, Norway.

Norafkan, M. (2013). Learnability of cultural models through authentic materials: Focus on metaphorical competence and conceptual fluency (Doctoral dissertation, Simon Fraser University). Retrieved July 2015, from http://summit.sfu.ca/system/files/iritems1/13447/etd7884mnorafkan.pdf

Punter, D. (2007). Metaphor. Routledge: Oxon.

Ritchie, D. L. (2006). Context and connection in metaphor. New York: Palgrave Macmillan, Antony Rowe Ltd, Chippenham and Eastbourne.

Savignon, S. J. (1972). Communicative competence: An experiment in foreign Language teaching. Philadelphia: The Centre for Curriculum Development, Inc.

Talebinezhad, M. R. (2007). Conceptual fluency and metaphorical competence in second Language acquisition: Two sides of the same coin? Journal of Social Sciences and Humanities of Shiraz University, 26(4), 87-107.

Tyler, A. (1995). The co-construction of cross-cultural miscommunication: Conflicts in perception, negotiation, and enactment of participant role and status. Studies in Second Language Acquisition, 17(2), 129-152. 